\title{
Modeling the Effects of Area Closure and Tax Policies: A Spatial-Temporal Model of the Hawaii Longline Fishery
}

\author{
UJJAYANT CHAKRAVORTY \\ Emory University \\ KEIICHI NEMOTO \\ University of Hawaii
}

\begin{abstract}
We develop an economic model for a multi-species fishery that incorporates the spatial and temporal distribution of effort and fish stocks. Catchability coefficients and initial stocks are estimated from catch and effort data for each specific location. Vessels are allocated over space and time to locations of maximum profit, which decline with harvest because of stock externalities. A supply function for labor allocation in the fishery is estimated. The simulated model is applied to the Hawaii longline fishery. The economic impacts of regulatory policies, such as reduction of inshore gear conflict and conservation of offshore turtle populations, are examined.
\end{abstract}

Key words Area closures, fisheries, longline fisheries, regulation, spatialtemporal models.

\section{Introduction}

Individual Transferable Quotas (ITQs) have been heralded by many fishery economists as the panacea for the management problems that beset most of the world's fish stocks. In a comprehensive review of the regulatory experience with ITQs, Squires, Kirkley, and Tisdell (1995) suggest that many countries have preferred input controls to ITQs in fisheries with multiple species and bycatch problems, as well as in situations where the costs of monitoring, enforcement, and resource assessment are significant. Other "second best" management measures, such as area closures and gear restrictions, have been adopted in more complex fisheries in several countries such as the United Kingdom, Norway, and Italy. Area and seasonal closures have also been popular in the management of migratory species, such as tuna in the Atlantic and Pacific Oceans (Gribble and Dredge 1994).

There is a large body of literature (see survey by Townsend 1990) that examines

AUTHOR: Ujjayant Chakravorty is ??? in the Department of Economics at Emory University, Atlanta GA 30322 , email: unc@emory.edu. Keiichi Nemoto is ??? in the Department of Natural Resources and Environmen-

Please tal Management at the University of Hawaii at Manoa, Honolulu, HI 96822, email: keiichi@ hawaii.edu. provide Seniority of authorship is equally shared.

titles of We owe a major debt to KinPing Tse for research assistance during the early phase of this research. authors. We thank Marcia Hamilton and Sam Pooley of the National Marine Fisheries Service Honolulu Laboratory for access to NMFS data and to Chris Boggs, Pierre Kleiber, John Sibert, Mike Travis, John Yanagida. We especially thank Sam Pooley for numerous suggestions and insights. This paper is funded by Cooperative Agreement Number NA67RJ0154 from the National Oceanic and Atmospheric Administration. The views expressed herein are those of the authors and do not necessarily reflect the views of NOAA or any of its subagencies. 
the economic and biological impacts of alternative regulatory policies, such as ITQs, and various forms of limited entry programs (e.g., gear restrictions). Most published studies have either focused on a single regulatory instrument, such as a quota on harvest or gear restriction, or a combination (Moussali and Hilborn 1986; Stollery 1984). Other analyses have attempted to endogenize the length and timing of closures in a programming model of stock recruitment (Watson, Die, and Restrepo 1993). These models, by and large, implicitly assume away substitution effects of area closures; i.e., when a certain fishing ground is closed, effort may be reallocated elsewhere. Several studies suggest that these substitution effects may be quite significant. For example, Cadrin et al. (1995) point out that when stocks are migratory, closure of inshore areas to more efficient vessels, "may not confer the expected benefits because fishing effort will be displaced to unprotected areas." Closure of inshore fishing areas led to increased allocation of effort to onshore fishing grounds in the Gulf of Mexico brown shrimp fishery (Gracia 1997). Very recently, lawyers for the Earthjustice Legal Defense Fund concerned about turtle bycatches in the North Pacific successfully argued that substitution of boats to other regions will minimize the welfare impacts of a moratorium on fish harvests in the North Hawaiian Ocean. As a result, U.S. District Judge David Ezra took the "unprecedented" step of restricting Hawaii longliners from fishing north of 28 degrees latitude (TenBruggencate 1999).

In what follows, we examine the economic impacts of area closure and tax policies by developing a model which explicitly incorporates both the spatial and dynamic elements. The model has several unique features that include: $(i)$ estimation of the catch-abundance relationship for a multi-species fishery by spatial location; (ii) sequential allocation of vessels over a spatial grid using a crew-profit maximizing criterion; and (iii) estimation of a labor supply function based on the labor-leisure tradeoff. The model is applied to the spatial and dynamic allocation of longline vessels in the Hawaii pelagic fishery. Model results are found to predict actual vessel allocation data reasonably accurately. The model is then used to generate economic impacts under alternative area closure restrictions and tax policies.

The differential impact of area closure policies that reduce inshore gear conflict and turtle bycatch in offshore fisheries is compared with an increase in the tax on harvest. It is found that harvest taxes have a minimal effect in achieving conservation objectives relative to area closures. An increase in the harvest tax would have a small effect on the reduction of aggregate fishing effort and catch, but would significantly reduce crew wages and boat owner incomes. Area closure policies that reduce turtle bycatch in the northern latitudes also block access to lucrative swordfish fishing grounds, but they have a relatively small impact on vessel profits. This is because boats are able to switch to inshore fishing areas. Policies that reduce gear conflict in inshore areas have the smallest impact on crew income and result in reduced harvests of the major inshore species.

While the individual elements of the proposed model are not novel, we believe that the inclusion of a spatially, non-uniform distribution of fish stocks and harvesting costs in obtaining the equilibrium allocation of vessels over time and space helps develop a modeling framework which is powerful in predictive capacity and policy analysis. The spatial feature allows for differential accounting of vessel travel costs from port and fishing costs by location. The dynamic nature of the model allows for stock externalities and exogenous changes in demand and cost parameters. In the longer term, discounting can be easily incorporated. In future work, biological information on the spatial migration of pelagic fish stocks can be included to determine instantaneous fish stocks net of harvest and migration. Extension to multiple ports of origin and political jurisdictions is straightforward.

The following section details the elements of the proposed model. The calibra- 
tion of the model using data from the Hawaii pelagic fishery is then described. This is followed by a demonstration of the model application by examining impacts of regulatory policy changes. Finally, a conclusion summarizes the paper.

\section{The Model}

The model is based on a standard framework of maximization of fleet profit by riskneutral fishermen in the short run, where the allocation of fishing effort is determined over space based on the comparison of net revenues from each fishing location. The fishery can be thought of as a regulated open-access fishery, where seasonal closures are used to achieve regulatory objectives such as species and bycatch conservation. Net revenues, in turn, are dependent on stock sizes of each species and allocated fishing effort in fishing locations, as well as exogenous fish price and catchability of each species. Price and various stock sizes across fishing regions in each period influence the fleet revenue per trip, while the distance between the harbor and each fishing area affect travel costs. Fishing sets are divided according to the primary target (e.g., tuna or swordfish) as explained below, which, in turn, affects the catchability of different species as well as fishing costs per set. Thus, the choice of set types within a trip also influences the trip's profitability. As more trips are allocated into a particular fishing area, the expected revenue per trip from the area (and the net return) diminishes due to the stock externality. In equilibrium, the average net returns per trip are equalized across locations.

\section{Catch Function}

Consider a fishery in which there are $I$ species of fish (e.g., swordfish, bigeye, and yellowfin) denoted by $i=1, \ldots, I$ and $K$ fishing areas or locations, indexed by $k=1$, $\ldots, K$. Stocks of different species are assumed to be known at the beginning of a given time period in each area. These time periods are chosen to be sufficiently short, such that in each area stock changes within a period due to fish reproduction, natural mortality, and stock migration across areas can be ignored; i.e., fish stocks within a period are expected to decrease only due to harvesting.

The catch for species $i$ in area $k$ over this unit time period is given by:

$$
C_{i, k}=\left(1-e^{-f\left(E_{k}, \gamma_{i}\right)}\right) B_{i, k}
$$

where $B_{i, k}$ and $\left(1-e^{-f}\right)$ are the respective fish stock and fishing mortality rate for species $i$ in area $k$. As specified in (1), the fishing mortality rate is an increasing function of fishing effort expended in area $k$ and exhibits diminishing marginal returns. Note that the fishing mortality rate must, by definition, be confined to the unit interval and is always less than unity. We also assume that the fish stock is "infinitely diffusive" within area $k$; i.e., the density of fish is linearly related to the residual stock size and is distributed uniformly within each fishing area (Clark 1985). $\gamma_{i}$ is a vector of the catchability coefficient for species $i, E_{k}$ is a vector of fishing effort (e.g., number of hooks) in area $k$, and $B_{i, k}$ is the fish stock for species $i$ in area $k$. In equation (1), $f$ is defined as a linear sum of effort by set types:

$$
f\left(E_{k}, \gamma_{i}\right)=\sum_{s} \gamma_{i, s} E_{k, s}
$$


where $s$ represents alternative set types (e.g., targeting tuna or swordfish), $\gamma_{i, s}$ and $E_{k, s}$ are the catchability coefficient and the amount of fishing effort by set type $s$, respectively. Later in the empirical model, we define one unit of fishing effort as 1,000 hooks. Vessel trips need to be differentiated by whether they target swordfish or tuna (or both), since the cost structure and the catchability vary depending on the species targeted during the trip. A slightly more generalized form of equation (1) has been used by Clark (1985) and Deacon (1989), although they do not consider heterogeneity in the targeting of species.

\section{Revenue from a Fishing Trip}

We assume that ex-vessel fish prices are given. Although not attempted here, a demand function for each species can be substituted at the cost of additional model complexity. Implicitly, we assume that each boat has perfect knowledge of the fish stock in area $k$. Then the total revenue from fishing in area $k$ is obtained by summing over revenues from each species. The average revenue per trip in area $k, A R_{\text {Trip, }}$, can then be expressed as:

$$
A R_{\text {Trip }, k}=\frac{\sum_{i} P_{i} C_{i, k}}{N_{k}}=\frac{\sum_{i} P_{i}\left(1-e^{-f\left(E_{k}, \gamma_{i}\right)}\right) B_{i, k}}{N_{k}}
$$

where $P_{i}$ is the price of species $I$, and $N_{k}$ denotes the total number of fishing trips to area $k$ per unit time period. It is easy to see from equation (3) that average revenue will increase with fish prices and initial stock, and decrease with the number of trips.

We assume that all boats that target the same species (tuna or swordfish) are identical and that once the boat reaches a fishing location $k$, they each conduct the same number of fishing sets over an equal number of days, and expend the same fishing effort for each set type. The assumption of identical effort across boats targeting tuna or swordfish may be reasonable for an industry with homogeneous gear (e.g., longliners), in which most boats would have roughly similar storage capacity for bait and harvested fish. Second, the time spent fishing may be limited since the quality of the freshly harvested fish on board begins to decline rapidly with time.

Let $F D$ denote the number of fishing days per trip. Since each boat can change types (e.g., targeting swordfish or tuna) during a single trip, $F D=\Sigma_{s} F D_{k, s}$, where $F D_{k, s}$ is the number of days a boat is of type $s$ per trip in area $k$. It implies that the number of days a boat chooses to target tuna or swordfish may vary, but the total number of fishing days per trip is fixed. The allocation of set type within a trip is a choice variable. Let $\bar{E}_{s}$ denote the amount of fishing effort by set type $s$, which is constant. Then the aggregate amount of fishing effort in area $k$ by set type $s$, is:

$$
E_{k, s} \equiv \bar{E}_{s} \cdot F D_{k, s} \cdot N_{k}
$$

\section{Cost Structure and Crew Wage}

We incorporate features of the labor-employment relation that have a bearing on apportioning of revenue and costs from fishing (Plourde and Smith 1989). For this purpose, we classify the costs of fishing into two categories: fixed and variable (i.e., 
operational) costs. In the share system that is prevalent in the Hawaii longline fishery (Hamilton, Curtis, and Travis 1996), fixed costs are usually borne by the vessel owner and consist of overhead expenses (e.g., maintenance, mooring, and depreciation charges), which do not depend directly on the fishing trip and are more or less fixed on an annual basis. Therefore, we assume that fixed costs do not affect the trip allocation decision in our short-run model.

The variable costs are the expenses incurred during the fishing trip (e.g., fuel, bait, and gear). This can be further broken down into costs incurred while traveling to area $k$ and fishing in that location. We assume away travel costs within area $k$, which may be reasonable because they are likely to be a small fraction of the costs of traveling from port. For simplicity, each trip involves direct travel to the chosen destination and return to port; i.e., fishing in multiple areas within the same trip is not allowed. Multiple locations will complicate the computation of travel costs and will necessitate making assumptions about the sequence of fishing locations within the same trip. Consultations with fishery economists (e.g., Pooley 2000) suggest that it is quite possible that vessels move around within a given area $k$, which by itself is an "artificial" construct. If that happens, the model is a good enough approximation, except that we are not taking into account the additional travel costs. It is perhaps unlikely that lots of vessels move across regions in a single trip. On the other hand, returning boats could be picking up additional catches during their trip to the port, and we do not consider it in our model. Future extensions of the model could include multiple fishing locations within a single trip.

Taxes on the harvest are included as a percentage of the total revenue from a trip. Variable costs including taxes are shared equally by the owner and crew. The owner is usually absentee, while we denote all hands on board, including the captain, as crew. The net revenue from a trip to area $k, N R_{k}$ is then given by:

$$
N R_{k}=A R_{\text {Trip }, k}(1-\tau)-\left(\sum_{s} a_{s} \cdot F D_{k, s}+b \cdot T D_{k}\right)
$$

where $\tau$ denotes the tax rate, cost parameters $a_{s}$ and $b$ represent the average daily variable costs of fishing with set type $s$ and traveling, respectively, and $T D_{k}$ is the number of days spent in traveling from port to destination $k$ and back. As mentioned before, since all boats spend an equal number of fishing days per trip, the total number of fishing days per trip, $F D$, is equal across trips. On the other hand, the number of travel days, $T D_{k}$, can be estimated by dividing twice the distance to area $k$ from port by average vessel speed.

The incomes accruing to the vessel owner and crew from a trip to area $k$ are given by:

$$
O I_{k}=(1-\lambda) \cdot N R_{k}
$$

and

$$
C I_{k}=\lambda \cdot N R_{k}
$$

where $O I_{k}$ and $C I_{k}$ and $(1-\lambda)$ and $\lambda$ denote the respective incomes and relative shares of net revenue accruing to the owner and crew.

The crew income from a trip in equation (7) or the crew wage per day, which is the crew income divided by the total number of trip days, may be used as a measure of wage. However, both indicators may be biased when comparing wages across 
fishing areas due to the variation in the distance of the fishing location from port. We remove this bias by normalizing wages with respect to distance employing a procedure detailed in Appendix 1, which yields $N C W_{k}$, the normalized crew wage for a trip to area $k$. Finally, let $N C W$ denote the weighted average normalized crew wage for the entire fishery per unit time period, obtained as:

$$
N C W=\frac{\sum_{k} N C W_{k} \cdot N_{k}}{\sum_{k} N_{k}}
$$

Finally, labor allocation per period in the fishery, measured in vessel-days, is obtained by summing both fishing and traveling days over all trips to all fishing areas as:

$$
V D=\sum_{k}\left(F D+T D_{k}\right) N_{k}
$$

where $V D$ is the aggregate amount of labor allocation in vessel-days per time period.

Given exogenous fish prices, a derived demand function for labor is obtained through optimal allocation of vessel trips over space. Since vessels are assumed identical in every respect, it is straightforward to distribute the representative vessel trip spatially starting from the fishing location that yields the maximum normalized crew wage to the crew (i.e., $N C W_{k}$ ). Note that the allocation of sets (tuna and swordfish) within each trip is endogenous. As vessels get assigned to locations generating maximum normalized crew wage, subsequent harvests in that location decline because of stock externality. Other competing fishing locations become more profitable. Thus, as the aggregate number of trips-all of which consist of an equal number of fishing (though not travel) days-increases, the marginal, and hence the average trip wage decreases. Because of the discrete nature of the problem of allocating a fixed number of vessel trips, the equilibrium normalized crew wage will only be approximately equal across locations. In a model where the number of boats is infinitely divisible, $N C W_{k}$ and $N C W$ are exactly equal. A plot of the normalized wage index as a function of the aggregate amount of vessel-days yields a downward-sloping derived demand function for labor. Note that this demand function may shift in response to changes in fish prices or the initial distribution of the fish stock.

\section{Labor Supply and Equilibrium Allocation of Trips over Space}

The fishing industry is ideally suited for modeling the labor supply behavior of fishermen. This is because most fishermen are self-employed, and boat captains generally have the power to decide if, when, and where to undertake a fishing trip. Furthermore, as pointed out by Gautam, Strand, and Kirkley (1996), unlike other professions in which labor and leisure activities coexist almost on a daily basis, commercial fishing in the high seas is demanding work coupled with limited leisure opportunities. This makes the disutility of spending another day fishing or staying at sea an important determinant of the labor supply decision. Assuming a fixed number of fishing vessels, the aggregate labor supply function can be expressed as:

$$
V D=S_{L}(N C W, M)
$$

where $M$ is income from non-fishing activities. Labor supplied by the crew (includ- 
ing captain) is expected to increase with the normalized crew wage, $N C W$, and it may, in the short-run exhibit backward-bending properties (as in Gautam, Strand, and Kirkley 1996). In general, non-fishery income $M$ may affect the labor-leisure substitution. However, for commercial fisheries as considered here, $M$ may be relatively small, and in any case it is difficult to obtain data for non-fishery income earned by fishermen. It is, therefore, ignored in the empirical estimation.

In order to econometrically estimate the labor supply function in equation (11), we obtain $N C W$ and $V D$ using actual data (Kennedy 1992). That is, the actual numbers of catches and vessel trips to area $k$ are used in equation (3) as compared to the use of equations (1-9) in the calculation of the derived demand function obtained from stock and price data. The derived demand function for labor is expected to shift in response to changes in fish prices or the distribution of fish stocks, while the labor supply function remains constant across periods. Finally, the equilibrium levels of $N C W$ and $V D$ are obtained by equating the derived labor demand with the estimated labor supply function from equation (11).

\section{Application to the Hawaii Longline Fishery}

In this section, we apply the above model to the Hawaii longline pelagic fishery. The Hawaii commercial fishery has grown rapidly since 1987, with annual commercial value estimated at roughly $\$ 60$ million (WPRFMC 1997). Longline vessels account for more than $80 \%$ of gross revenue, the remaining being from baitboat (poleand-line skipjack), handline, and trolling. For the purposes of this study, we only deal with longline vessels, which are reasonably homogenous in terms of fishing technology and other vessel characteristics. The major species targeted by the longline fishery are broadbill swordfish and bigeye tuna (He, Bigelow, and Boggs 1997), while yellowfin and albacore tunas and striped marlin also represent a significant share of the total ex-vessel revenue. Together, these five species accounted for approximately 90\% of gross revenue in 1995 .

We construct a spatial grid that divides the fishery into 56 five-by-five degree (latitude and longitude) squares centered in the Main Hawaiian Islands (MHI). These areas are located between latitude $5^{\circ} \mathrm{N}$ to $45^{\circ} \mathrm{N}$ and longitude $140^{\circ} \mathrm{W}$ to $170^{\circ}$ E. Each five-degree square is defined using its southeast corner as the reference point; e.g., the square between latitudes $15^{\circ}$ and $20^{\circ} \mathrm{N}$ and longitudes $140^{\circ}$ and $145^{\circ} \mathrm{W}$ is labeled as $15 \mathrm{~N} 140 \mathrm{~W}$, as per a classification system developed by Curran, Boggs, and He (1996).

Catch and fishing effort data from the 1995 longline logbook, collected by the National Marine Fisheries Service (NMFS) (Dollar and Yoshimoto 1991) are aggregated by five-by-five degree squares and by month. The data suggests that 1,125 trips (corresponding to 11,129 sets and about 13.3 million hooks) were taken by 110 active longline vessels in 1995 (WPRFMC 1997). That is, on average each longline fishing trip lays approximately 10 sets-one set each fishing day.

\section{Swordfish vs Tuna Sets}

One complication that needs to be considered in empirical work is the targeting strategy of the vessel. Each boat can target swordfish or tuna (bigeye and yellowfin) on any given fishing day, while the remaining two species, albacore and striped marlin, are caught mainly as bycatch. Targeting these different species imposes distinct fishing and cost characteristics on the boat. For example, swordfish sets are soaked overnight and they use more expensive bait (squid) and other devices (lightsticks). 
Tuna sets are soaked in daylight, and use cheaper samma (saury, Cololabis saira) as bait. The catchability coefficients [from equation (1)] would be different for each set, since swordfish (tuna) targeting would lead to bigger swordfish (tuna) catches, ceteris paribus. Allocation of sets is done by inspecting logbook data and designating each set as swordfish or tuna set depending on whether they satisfy the above qualitative criteria. About $11 \%$ of the sets did not fall clearly into any category; e.g., a set that soaked in the night, used squid as bait, but did not use any lightsticks. These were allocated by looking at which of the above criteria they matched more closely.

Given the two fishing strategies or set types, the specification of the function $f$ in equation (2) can be simplified as:

$$
f\left(E_{k}, \gamma_{i}\right)=\gamma_{i 1} E_{k 1}+\gamma_{i 2} E_{k 2}
$$

where subscripts 1 and 2 denote tuna and swordfish sets, respectively. Since the average number of hooks used in a swordfish set (820) was different from a tuna set $(1,498)$, the fishing effort levels in area $k$ by type 1 and 2 can be expressed from equation (4) as $E_{k 1}=1.498 F D_{k 1} \cdot N_{k}$ and $E_{k 2}=0.820 F D_{k 2} \cdot N_{k}$. Here $\left(F D \cdot N_{k}\right)$ and $\left(F D_{k 2} \cdot N_{k}\right)$ represent the total number of tuna and swordfish sets conducted in area $k$, and $F D_{k 1}+F D_{k 2}=10$ since the sum of swordfish and tuna sets per trip must equal the total fishing days, and we define one unit of fishing effort as 1,000 hooks.

\section{Estimating Catchability Coefficients and Fish Stocks}

Given the two distinct fishing strategies, two sets of catchability coefficients for each species (i.e., for tuna and swordfish sets) are estimated from monthly catch and effort data, details for which are given in Appendix 2. The results are summarized in table 1 . The catchability for swordfish with a tuna set was very low (0.0002), which implies that a tuna set catches very few swordfish. Also, for a given stock size and unit effort, a swordfish set catches 22 times more swordfish than a tuna set. The table also suggests that a swordfish set catches more bigeye and yellowfin tunas than even a tuna set, although fishermen may actually prefer to catch these tunas using the cheaper cost of a tuna set. Catches of albacore and striped marlin were higher from tuna sets than from swordfish set. These results are very similar to that of Okamoto (1999).

The catchability coefficients for the five major species, as well as monthly effort and catch data, are used to estimate the initial size of the monthly fish stock $B_{i, k}$ in each location from equation (1). That is, the estimated fish stock (population of species $i$ in location $k$ ) is assumed to be "in place" at the beginning of each month,

Table 1

Estimation Results for Catchability Coefficients by Species and by Fishing Strategies

\begin{tabular}{lccc}
\hline & \multicolumn{2}{c}{ Catchability Coefficient } & \\
\cline { 2 - 3 } & $\begin{array}{c}\text { Tuna Set } \\
\left(\gamma_{i 1}\right)\end{array}$ & $\begin{array}{c}\text { Swordfish Set } \\
\left(\gamma_{i 2}\right)\end{array}$ & $\begin{array}{c}\text { Catchability } \\
\text { Ratio } \\
\left(\gamma_{i 2} / \gamma_{i 1}\right)\end{array}$ \\
\hline Species & 0.00022 & 0.00483 & 22.453 \\
Bwordfish & 0.00338 & 0.00738 & 2.181 \\
Yellowfin tuna & 0.00378 & 0.01224 & 3.237 \\
Albacore tuna & 0.00431 & 0.00058 & 0.135 \\
Striped marlin & 0.00248 & 0.00195 & 0.788 \\
\hline
\end{tabular}


but depletes with harvesting as trips are allocated at each location. A new stock is estimated at the beginning of each month. In one sense, the model simplifies the inflow and outflow of fish migration in each grid by assuming that migration could only occur instantaneously at the point of transition between successive time periods; i.e., at the beginning of each calendar month. Notice that a calendar month is only an arbitrary device, and the model could be built with weekly price, catch, and effort data, if available, although allocation of trips that usually last longer than a week, may be problematic.

\section{Expected Revenue from a Trip}

Monthly fish prices are assumed to be exogenously determined, since most fish is sold in markets in Japan and the U.S. mainland (WPRFMC 1995). Prices were computed using revenue data for each species collected by the Hawaii Department of Agriculture and Resources (HDAR 1995). Catch data is in terms of numbers of fish caught, and fish prices are in dollars per standard-sized fish, as shown in figure 1. Using equation (3), expected revenue in each location was computed from fish prices and estimated stocks. Since the aggregate revenue from the five major species was $92.82 \%$ of the total revenue reported in 1995, a correction factor of 1.0774 was applied to account for other minor species and side catches.

\section{Variable Costs of Fishing}

As mentioned earlier, we ignore fixed costs of fishing and focus only on variable costs and taxes. In Hawaii, longliners are legally obliged to sell their catch to the United Fishing Agency Ltd., which charges each vessel an auction fee equal to $10 \%$

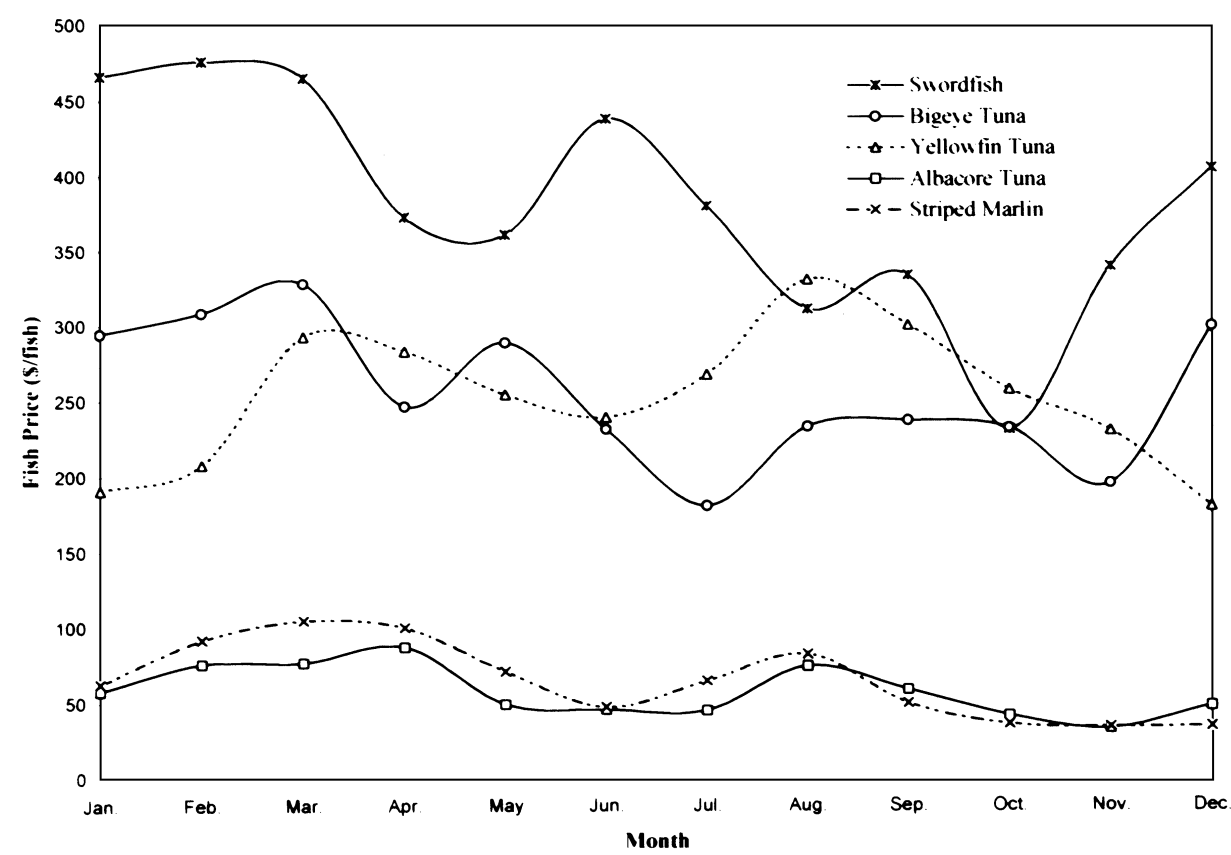

Figure 1. Average Monthly Fish Prices (\$/fish) 
of the total revenue from a fishing trip. The excise tax rate is an additional $0.5 \%$ of the total revenue. Both the auction fee and the excise tax are shared equally between the owner and crew and are a fixed proportion of gross trip revenue (Hamilton, Curtis, and Travis 1996).

Variable costs, including the cost of food, oil, fuel, bait, lightstick, ice, and miscellaneous gear, can be broken down according to their relationship to fishing or traveling activity. Food, oil, and fuel are consumed for both, while expenses on bait, lightsticks, ice, and miscellaneous fishing gear occur only during fishing. That is, the cost of a fishing day is much higher than the cost of a travel day. Table 2 details the breakdown of the variable costs. Based on the survey by Hamilton, Curtis, and Travis (1996), the average daily costs for food and oil are $\$ 81.54$ and $\$ 9.41$, respectively. The cost of fuel, is on average, higher on a travel day (\$250.56) than on a fishing day (\$219.11). The variable cost per travel day is $\$ 341.51$ as shown in the table.

Another complication in the calculation of variable costs is the higher expense of targeting swordfish relative to the tuna species (i.e., bigeye and yellowfin). The variable cost of fishing depends on a vessel's targeting strategy. It is likely to be higher for targeting swordfish and lower for targeting (bigeye) tuna, due to more expensive bait, lightsticks and miscellaneous gear in the former. Specifically, the average variable cost per fishing day depends on the proportion of swordfish-targeted sets in the 10 sets per fishing trip. As indicated in table 2 , the cost of a fishing day is much higher than the cost of a travel day, and swordfish fishing is almost thrice as expensive $(\$ 2,062.61)$ as tuna fishing $(\$ 779.84)$. This yields the following formula for variable costs for a trip to area $k$ :

$$
V C_{k}=\left(779.84+1282.77 \times r_{s w, k}\right) \times 10+341.51 \times T D_{k}
$$

where $r_{s w, k}$ is the share of swordfish sets in the total. The above equation implies that the variable costs per trip will increase about $\$ 1,283$ by substituting a swordfish set for a tuna set.

Table 2

Estimated Average Daily Variable Costs (\$/day)

\begin{tabular}{lrcc}
\hline & \multicolumn{3}{c}{ Fishing day } \\
\cline { 2 - 3 } Items & Tuna Set & Swordfish Set & Travel Day \\
\hline Food & 81.54 & 81.54 & 81.54 \\
Oil & 9.41 & 9.41 & 9.41 \\
Fuel & 219.11 & 219.11 & $250.56^{\mathrm{a}}$ \\
Ice & 85.50 & 39.10 & \\
Bait & 272.88 & 652.42 & \\
Light-stick & 0.00 & 529.13 & 341.51 \\
Misc. gear & 111.40 & 531.90 & \\
\hline Total & 779.84 & $2,062.61$ & \\
\hline
\end{tabular}

Source: Hamilton, Curtis, and Travis (1996).

${ }^{a}$ In their survey, 37 out of 94 vessels surveyed found no fuel cost differentials between fishing and travel days, 9 reported higher fuel costs for fishing days, and the remaining 48 vessels reported higher fuel costs for travel days. The average fuel cost was $\$ 219.11$ per fishing day and $\$ 250.56$ per travel day. 


\section{Net Return and Normalized Crew Wage}

The net return for a trip to area $k$ and the normalized crew wage can then be expressed as:

$$
N R_{k}=\frac{\sum_{i} P_{i}\left(1-e^{-\left(\gamma_{i 1} E_{k 1}+\gamma_{i 2} E_{k 2}\right)}\right) B_{i, k}}{N_{k}} \times 1.0774 \times(1-0.105)-V C_{k}
$$

and

$$
N C W_{k}=\frac{0.50 \times N R_{k}}{10+0.2803 \times T D_{k}}
$$

where 0.105 is the total share of revenue paid out as auction fee $(10 \%)$ and excise $\operatorname{tax}(0.5 \%)$, and 0.2803 is the ratio of wages from a travel day relative to a fishing day (see Appendix 1), and the vessel owner and crew each collect 50\% of the residual profit (i.e., $1=0.50$ ) - more than $95 \%$ of Hawaii-based longline vessels follow the equal sharing rule (Hamilton, Curtis, and Travis 1996). These equations yield the derived demand for labor, as explained in the previous section.

\section{Estimation of Labor Supply}

To get the supply function, the monthly total revenue from trips to area $k$ was estimated using actual catch data, by region, from the 1995 longline logbook. Unfortunately, the logbook data available to us does not reveal the number of trips made by vessels to a specific location, only the total numbers of sets and hooks placed in each square by month. Since we assume that the exact 10 sets must be conducted in a single fishing location within a trip, dividing the total number of sets placed in each square by 10 yields the "actual" number of trips. The number of vessel-days, computed from equation (9), was aggregated by month and summarized in table 3 . The annual number of trips approximated was 1,165 , somewhat larger than the 1,125 total longline trips made in 1995 (WPRFMC 1997). One reason for this overestimation was that vessels tended to conduct more sets during distant-water fishing trips. Part of the error could also be due to errors in recording of logbook data.

Using a simplified specification of a labor supply function used by Battalio, Green, and Kagel (1981), the labor supply function was estimated as follows:

$$
\ln V D=2.2777(\ln N C W)-0.17178(\ln N C W)^{2}
$$

$$
(-21.67)
$$

where numbers inside the parentheses are $t$-ratios. The resulting adjusted $R^{2}$ and Durbin-Watson statistic were 0.6627 and 2.3809, respectively. Both parameters were significant at the $1 \%$ level. Since the crew would not go fishing if the expected wage was not high enough, $\ln V D \leq 0$ when $\ln N C W=0$, the intercept in equation (16) should be zero or negative. Because a positive, but insignificant, intercept was obtained in the preliminary estimation, the intercept was restricted to zero. The labor supply function obtained is illustrated in figure 2. Supply is increasing with $N C W$ when $N C W<\$ 757 /$ day, but it is backward-bending at higher values. 
Table 3

Data for Estimating the Fishing Labor Supply

\begin{tabular}{lcccc}
\hline Month & $\begin{array}{c}\text { Number of } \\
\text { Fishing Trips }^{\mathrm{a}}\end{array}$ & $\begin{array}{c}\text { Labor } \\
\text { (vessel-days) }\end{array}$ & $\begin{array}{c}\text { Normalized } \\
\text { Crew Wage } \\
(\$ / \text { day) }\end{array}$ & $\begin{array}{c}\text { Total Ex-vessel } \\
\text { Revenue of Longline } \\
\text { Industry (million \$) }\end{array}$ \\
\hline January & 99.1 & 1,687 & 1,168 & 4.67 \\
February & 99.3 & 1,913 & 1,182 & 5.08 \\
March & 102.5 & 1,861 & 1,151 & 5.13 \\
April & 104.5 & 2,003 & 683 & 4.07 \\
May & 120.3 & 2,052 & 569 & 4.05 \\
June & 105.4 & 1,971 & 659 & 3.91 \\
July & 87.6 & 1,604 & 348 & 1.43 \\
August & 61.3 & 1,289 & 170 & 1.25 \\
September & 64.5 & 1,225 & 130 & 3.21 \\
October & 90.3 & 1,382 & 450 & 4.44 \\
November & 11.7 & 1,878 & 464 & 41.81 \\
December & 118.2 & 2,047 & 841 & \\
\hline Total & $1,164.7$ & 20,913 & 651 & \\
\hline
\end{tabular}

Source: NMFS longline logbook data (1995)

a Actual aggregated number of sets divided by 10 fishing days per trip.

Ex-vessel revenues from the five major species shows that the longline industry earned more than $\$ 4$ million per month during the first quarter and in December, and much less during the other months, particularly from July to November. The above data indicate that the backward-bending supply curve may be reasonable.

\section{Simulating the Hawaii Longline Fishery}

The equilibrium allocation of monthly trips that equates demand and supply of labor for the entire industry is determined using a simulation algorithm written in the programming language Turbo $\mathrm{C}++$. Note that there are 12 different demand functions, since stocks and prices vary by month, but only a single estimated supply function. Results are only shown in figure 2 for the months of March and August 1995, respectively, when the derived demands for labor are large and small.

Model results for the baseline year 1995 are compared with the actual distribution of fishing sets in the Hawaii longline fishery, shown in figure 3 . In order to investigate the importance of the leisure-labor tradeoff in the estimation of the supply function, an alternative model in which there is no income effect on the consumption of leisure (i.e., days on shore) is also presented in the figure. The latter model ignores the fisherman's disincentive to supply labor brought on by higher trip wages. Without this effect, the supply curve is horizontal; that is, fishing trips are allocated until labor demand is equal to the normalized crew wage computed from 1993 wage data (Hamilton, Curtis, and Travis 1996). As shown in figure 3, the model without the labor-leisure tradeoff demonstrated poor fitness. For example, the number of trips allocated was overestimated in the first quarter (particular in March) when trip revenue is relatively high (table 3 ) due to higher fish prices and stock abundance, and underestimated during April to November (no trips were allocated during August and September) when trip revenue was relatively low. This suggests that overestimation may have been caused because the disincentive to supply labor 


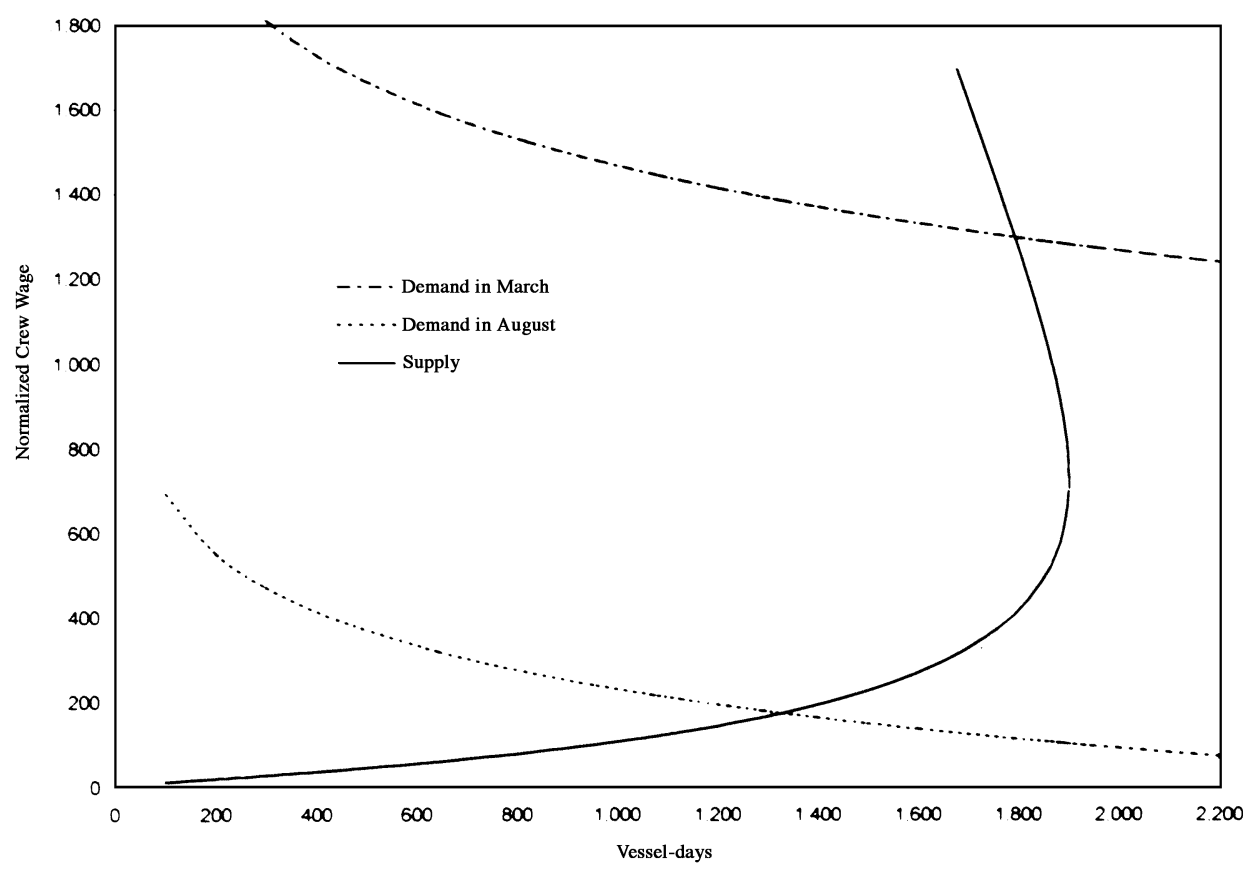

Figure 2. Derived Demand (in March and August) and Supply Curves for Labor

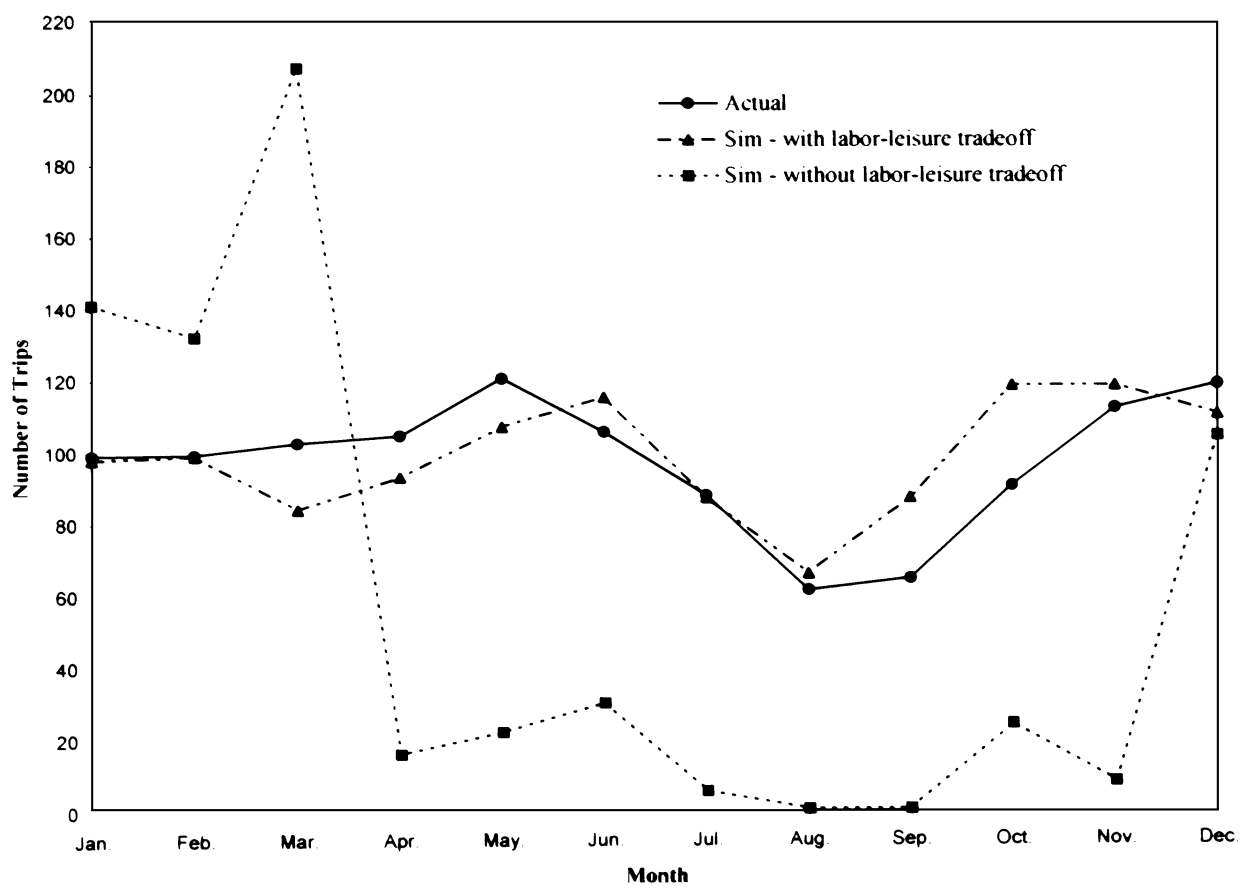

Figure 3. Number of Allocated Fishing Trips, 1995: Actual and Simulated (With and Without the Labor-Leisure Tradeoff) 
when crew wages were high in the first quarter was ignored. This comparison suggests that incorporation of the leisure-labor tradeoff may be significant in modeling fishermen's behavior, as suggested by Gautam, Strand, and Kirkley (1996), and could be explored in more detail in future work.

On the other hand, the model with the labor-leisure tradeoff performs markedly better in tracking the actual allocation of boats. The Mean Absolute Percentage Error (MAPE) was $11.4 \%$, while that without the labor-leisure tradeoff was more than $70 \%$. However, gaps between the actual and predicted numbers of trips still remain, as shown in figure 3 . The simulated number of trips is somewhat underestimated from March to May, and overestimated from September to November.

A large part of the difference can be explained by the difference in fishing locations and the number of swordfish sets from optimization and the actual spatial distribution as shown in table 4. For instance, in March and April, only four trips are allocated to two fishing regions near the Main Hawaiian Islands (MHI: 20N155W and $15 \mathrm{~N} 155 \mathrm{~W})$, although more than 40 trips were allocated in reality. However, relatively more trips are allocated in other areas, such as north of $30^{\circ} \mathrm{N}$. On the other hand, from September to November, 43 more trips are allocated to the two MHI regions in the simulation, while 27 less trips are allocated to the regions north of $30^{\circ} \mathrm{N}$.

Part of the error may be due to the fact that vessels tend to fish in familiar locations, not necessarily in those which return maximum profits. There is also the difficulty of estimating catches for each species, as seen in the species-wise breakdown of actual and simulated catches given in table 5. It shows that the simulated aggregate catches of albacore and striped marlin were higher by $30 \%$ and $19 \%$, respectively, although those for swordfish and bigeye were higher by only $1 \%$ and for yellowfin lower by about $10 \%$. One possibility is that fishermen may not be explicitly incorporating revenues from albacore and striped marlin in their decision-making process because these are somewhat "undesirable" species, much less valuable than the other three, and take up scarce storage space in vessels (Kelleher 1997).

Some other factors that may contribute to the difference in results are: $(i)$ the assumption of identical vessels in terms of cost structure, speed, and other parameters, such as the number of lightsticks used per fishing set; (ii) perfect knowledge about fish prices and stocks in each fishing location; (iii) the assumption of costless switching between tuna and swordfish sets; and (iv) restriction to one fishing location per trip. In particular, certain groups of vessels use only one strategy (tuna or swordfish) for a long period of time, due to factors such as personal preference and other vessel-related physical constraints.

\section{Policy Simulation}

We use the model to examine the economic impacts of three proposed regulatory policies: $(i)$ the closure of two, five-by-five degree squares, including the fishing areas off the Main Hawaiian Islands to avoid gear conflicts; (ii) closure of all fishing areas north of $30^{\circ} \mathrm{N}$ for sea turtle conservation; and (iii) increase of auction fee from $10 \%$ to $20 \%$ for revenue generation.

\section{Reducing Gear Conflict: Closure of Areas near the Main Hawaiian Islands (Case 1)}

Limited entry restrictions such as area closure, are particularly appropriate in reducing short-run (or crowding) externalities (Townsend 1990). Several gear types often compete for the same species of pelagic fish, and the exclusion of a particular gear 
Table 4

Monthly Allocation (1995) of Longline Trips, Labor, and Normalized Crew Wage: Actual vs. Simulated

\section{Author: \\ Please provide table 4 as a simple text document. Tables as embedded pictures in a text document will not work.}

type would reduce crowding. In Hawaii, longline and surface fleets (trollers and handliners) have often fished in the same locations, especially within 20 nautical miles of the shore (Skillman, Boggs, and Pooley 1993). Historically, longline vessels have been excluded from fishing in certain regions from time to time. In recent years, troll and handline landings of several pelagic species (e.g., yellowfin) have declined substantially, while longline landings have increased (Pooley 1994). Other small commercial, charter, subsistence, and recreational boats operating near-shore have also been adversely affected.

We examine the impact of the year-round closure of two areas, $20 \mathrm{~N} 155 \mathrm{~W}$ (including Oahu and Maui) and $15 N 155 \mathrm{~W}$ (including a major part of the fishing areas close to the Big Island). The results are summarized in table 6. The importance of the closed areas can be seen from column $\mathrm{A}$ in the Baseline Case-for example, in 


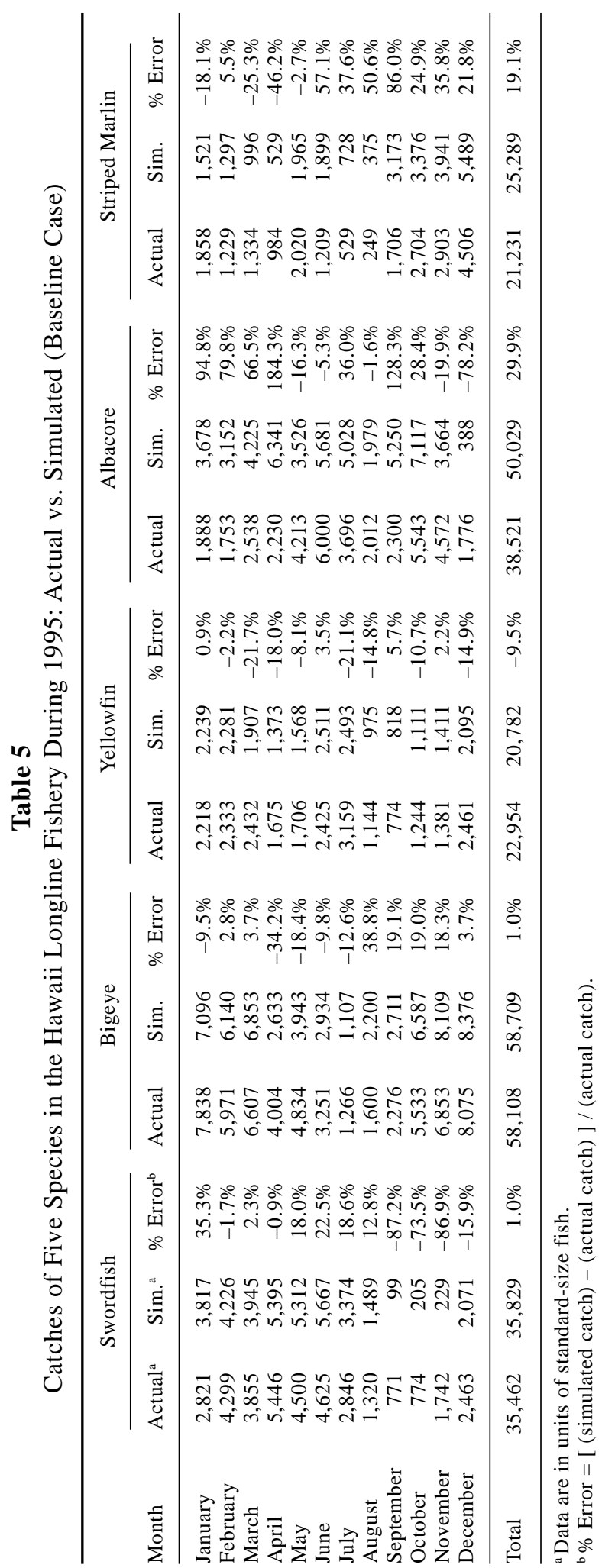


August, October, and November, more than $50 \%$ of the effort was centered on the two closed squares. The column (C - B) in table 6 shows the substitution of vessels into other areas as a result of area closure. Vessels compensate by fishing in distant waters, which results in an increase in costs and reduced wages as summarized in table 9 . The aggregate number of trips declines. Originally 303 trips were made into the closed areas, but with the closure policy, only 165 were reallocated, leading to a net decrease in 138 trips out of the original 1,182 trips-a decline of about $12 \%$.

\section{Conserving Sea Turtles: Closure of the North Fishing Areas North of} Latitude $30^{\circ} \mathrm{N}$ (Case 2)

Interaction between longline gear and endangered species, such as sea turtles, is continuously reported in the logbook data (Ito 1995). Leatherback, green sea, loggerhead, and olive ridley turtles were reported to have been accidentally caught a total of 84 times during 1994, although these interactions are widely believed to be underreported. Kleiber (1998) estimates that approximately 700 sea turtles were taken and around 100 were killed in 1995. Most of the loggerhead and leatherback turtles were caught in areas north of $30^{\circ} \mathrm{N}$. Fishery biologists, such as Nitta and Henderson (1993), have suggested the closure of fishing areas north of $30^{\circ} \mathrm{N}$ to conserve sea turtles, similar to the restrictions imposed in a recent decision by the U.S. District Court in Hawaii. The impacts of such a policy are simulated in table 7. Unlike the previous case, turtle conserving policies confine longline vessels to fishing areas closer to Hawaii; i.e., below $30^{\circ} \mathrm{N}$. Since more vessels now fish inshore, travel days decrease, which, in turn, enables more trips to be taken. Thus, aggregate number of trips shows a small increase. The ratio of swordfish sets to the total falls from $32 \%$ to $20 \%$, and swordfish catches, which mostly occur in the high seas, decline significantly (41\%) causing normalized crew wages to fall by $9 \%$ (table 9 ).

\section{Table 6}

Trip Allocation With and Without Area Closure:

Closure of Two Five-Degree Squares 20N155W and 15N155W

\section{Author: \\ Please provide table 6 as a simple text document. Tables as embedded pictures in a text document will not work.}


Table 7

Trip Allocation With and Without Area Closure:

Closure of All Five-Degree Squares North of $30^{\circ} \mathrm{N}$

\section{Author: \\ Please provide table 7 as a simple text document. Tables as embedded pictures in a text document will not work.}

\section{Increasing Auction Fee from 10\% to 20\% (Case 3)}

Increasing the auction fee may serve as a mechanism not only to reduce the profitability of fishing and thereby preserve fish stocks, but also as a means of generating additional revenue for the state. We, thus, examine the impacts of an increase in the auction fee rate from $10 \%$ to $20 \%$ (table 8 ). Since the auction fee is a fixed percentage of total revenue before netting variable costs, an increase in the fee results in a disproportionate negative effect on boats specializing in distant-water fishing whose variable costs tend to be higher. In particular, trips fishing north of $30^{\circ} \mathrm{N}$ are significantly affected (down by 35 trips), followed by those fishing between $5^{\circ} \mathrm{N}$ and $30^{\circ} \mathrm{N}$, as shown in table 8 . Counterintuitively, because of the backward-bending nature of the supply function, a higher auction fee increases the total number of trips when wages are higher particularly in the first quarter and in December. Correspondingly, this policy results in fewer fishing trips when labor supply is positively sloped; i.e., at low wage levels in the summer and fall (see table 8).

\section{Comparison of the Three Policies}

The differential impacts of the three policies on trip allocation, employment, total revenue (before taxes), government income through taxation, shared costs, profits, and wages are summarized in table 9 . All three policies reduce industry revenue. The total revenue from all longline trips will decline under all three policies, although the auction fee causes owner and crew incomes to decline significantly (18$21 \%$ ). Annual income accruing to vessel owners is simply $50 \%$ of the fleet profit divided by the number of active vessels. Thus, boat-owner incomes are most seriously affected by auction fees. Sustained low income may cause the net profit to fall be- 
Table 8

Trip Allocation with Baseline (10\%) and Increased (20\%) Auction Fee

\section{Author: \\ Please provide table 8 as a simple text document. Tables as embedded pictures in a text document will not work.}

low industry long-run average fixed cost, leading to exit from the industry. Some instances of exit from the Hawaii longline fishery to the U.S. Gulf Coast and Fiji have been observed in recent years (Travis 1999).

Crew incomes per trip are more negatively affected by turtle conservation (11\%) and least by reducing gear conflict. However, this comparison is overstated because average trip length is shorter under turtle conservation (boats fish closer to shore) than under gear conflict regulation. Hence, aggregate trips are higher. On the other hand, crew wages per day are affected more by gear conflict regulation $(8 \%)$ than by turtle conservation. However, normalized crew wage, which is net of travel days, is least affected by gear conflict policies $(2 \%)$, suggesting that turtle conservation has more of a negative impact on the crew (down by $9 \%$ ) than gear conflict policy.

The effect of alternative policies on conservation of fish stocks is also shown in the table. Interestingly, reduction of gear conflict leads to a significant reduction in catches for all the four species other than swordfish, since they dominate harvests close to port. While turtle conservation leads to a significant reduction of swordfish catches, it will actually increase catches of bigeye and yellowfin tunas and striped marlin. Although an auction fee hike will generate more tax revenues and significantly reduce fleet profits, the impact on fish conservation is minimal (except for swordfish), since there is very little substitution of vessels across locations, and the reduction in the number of trips is relatively small.

\section{Concluding Remarks}

This paper develops a spatial and dynamic model of the allocation of fishing effort that explicitly incorporates the spatial distribution of multiple fish stocks, stock externalities from fishing, and the relationship between vessel days and crew wages normalized across fishing locations. The model is used to simulate the monthly allocation of effort in the Hawaii longline fishery for the year 1995. The impact of regulatory decisions, such as inshore (reduction of gear conflict) and offshore (reduction of turtle bycatch) area closures and taxes on harvest are examined. Inshore area closure leads to vessels moving to more distant waters. While vessel-owner incomes 
Table 9

Comparison of Alternative Regulatory Policies: (i) Reducing Gear Conflict, (ii) Sea Turtle Conservation, and (iii) Increasing Auction Fee

\section{Author:}

Please provide table 9 as a simple text document. Tables as embedded pictures in a text document will not work. 
decline significantly, the effect on crew income per trip is smaller since they benefit from taking longer trips. Catches of inshore species are significantly reduced. Offshore area closure policies reduce swordfish catches by about $41 \%$. Average trip lengths decline by about $20 \%$, since boats fish closer to shore. On the positive side, substitution of boats into inshore areas and an increase in the number of trips allows for a relatively small adverse impact on fleet profits (5.3\%). An increase in the auction fee on harvest succeeds in skimming profits from the fishery and nearly doubles tax revenues but has little effect on conservation of fish stocks.

These results could be useful in assessing the impacts of regulatory policy on industry groups or on conservation objectives (Wilen 1993). There is an interesting asymmetry between the two area closure policies: reduction of gear conflict and turtle conservation. In the first, near-shore area closures lead to fewer trips of longer duration. The crew continues to receive wages from the increased travel days, but that does not benefit the boat owners. Thus, inshore area closures have a bigger impact on incomes accruing to boat owners. On the other hand, distant area closures, such as turtle conservation policies, lead to a larger number of lower-duration trips and has the opposite effect. Fiscal policy instruments, such as auction fee increases, have a significant effect on both parties because there is limited scope for substitution, while trips yielding marginal returns are no longer profitable.

The other major impact of turtle conservation is the increased harvesting of nearshore species such as yellowfin, bigeye, and striped marlin. Although not considered in the model, this can adversely affect catches by competing fleets, such as handliners and trollers, as well as recreational vessels. However, nearshore area closures increase swordfish catches marginally but have a positive impact on stocks of competing species.

Our results can be used to compute a rough implicit price of saving a loggerhead turtle. For example, Kleiber (1998) estimates that 66 loggerhead turtles were killed through interaction with longline gears in 1995. Then using our model results, the rough cost of adopting turtle conserving policies in terms of foregone profits to the longline fleet is approximately $\$ 14,100$ per turtle. These types of implicit valuations can be used by policymakers to analyze tradeoffs and make appropriate policy decisions.

The model developed in this paper can be improved in several different ways. The initial fish stock size is estimated based on current catch and hook data, assuming no inflow or outflow within a period but allowing for stock changes across each period; i.e., between successive months. Possible extensions include incorporating a migration function that allows for locational stock movements that are a function of stock differentials between adjacent grids. This function may display seasonal variations based on biological information on pelagic fish movements.

Improvements in future research could include estimation of the labor supply function using several years' data. Additional factors affecting fishery labor supply (e.g., time lag, income from non-fishing activities) could also be modeled in later work. The model does not account for interactions with other gear types (e.g., handline and troll). For example, a moratorium on distant shore fishing will increase inshore fishing by longline boats and may increase incidence of gear conflict. Lastly, the price and catch data used is for the most recent year available (1995), while the cost data is for 1993. This asymmetry could introduce errors in simulation, although it is implausible that the cost structure may have changed significantly within two years. New cost-earnings data from recent NMFS surveys could be used to further improve the predictive power of the model. 


\section{References}

Battalio, R.C., L. Green, and J.H. Kagel. 1981. Income-leisure Tradeoffs of Animal Workers. American Economic Review 71(4):621-32.

Boggs, C.H., and R.Y. Ito. 1993. Hawaii's Pelagic Fisheries. Marine Fisheries Review 55 (2):69-82.

Cadrin S.X., A.B. Howe, S.J. Correia, and T.P. Currier. 1995. Evaluating the Effects of Two Coastal Mobile Gear Fishing Closures on Finfish Abundance Off Cape Cod. North American Journal of Fisheries Management 15:300-15.

Clark, C.W. 1985. Bioeconomic Modelling and Fisheries Management. New York: John Wiley and Sons.

Curran, D.S., C.H. Boggs, and X. He. 1996. Catch and Effort from Hawaii's Longline Fishery Summarized by Quarters and Five Degree Squares. NOAA (National Oceanic and Atmospheric Administration) Technical Memorandum NMFS (National Marine Fisheries Service), NOAA-TM-NMFS-SWFSC-225.

Deacon, R.T., 1989. An Empirical Model of Fishery Dynamics. Journal of Environmental Economics and Management 16:167-83.

Dollar, R.A., and S.S. Yoshimoto. 1991. The Federally Mandated Longline Fishing Log Collection System in the Western Pacific. Honolulu Laboratory, Southwest Fisheries Science Center, NMFS, NOAA. Administrative Report H-91-12.

Gautam, A.B., I.W. Strand, and J. Kirkley. 1996. Leisure/Labor Tradeoffs: The Backwardbending Labor Supply in Fisheries. Journal of Environmental Economics and Management 31:352-67.

Gracia, A., 1997. Simulated and Actual Effects of the Brown Shrimp, Penaeus aztecus, Closure in Mexico. Marine Fisheries Review 59(2):18-24.

Gribble, N., and M. Dredge. 1994. Mixed-species Yield-per-recruit Simulations of the Effect of Seasonal Closures on a Central Queensland Coastal Prawn Trawling Ground. Canadian Journal of Fisheries and Aquatic Sciences 51:998-1011.

Hamilton, M.S., R.A. Curtis, and M.D. Travis. 1996. Cost-Earnings Study of the Hawaiibased Domestic Longline Fleet. NOAA SOEST 96-03.

HDAR (Hawaii Division of Aquatic Resources). 1995. Hawaii Fisheries Statistics Fishermen's Catch Report 1995. Unpublished Data Provided by Department of Land and Natural Resources, Division of Aquatic Resources, State of Hawaii, USA.

He, X., K.A. Bigelow, and C.H. Boggs. 1997. Cluster A of Longline Sets and Fishing Strategies within the Hawaii-based Fishery. Fisheries Research 31:147-58.

Ito, R.Y. 1995. Annual Report of The 1994 Hawaii-based Longline Fishery. Honolulu Laboratory, Southwest Fisheries Science Center, NMFS, NOAA. Administrative Report H95-08.

Kelleher, J. 1997. Survey of Hawaii Longline Fisheries. University of Hawaii.

Kennedy, P. 1992. A Guide to Econometrics (3rd ed.). Cambridge: The MIT Press.

Kleiber, P. 1998. Estimating Annual Takes and Kills of Sea Turtles by the Hawaiian Longline Fishery, 1991-97, from Observer Program and Logbook Data. Honolulu Laboratory, Southwest Fisheries Science Center, NMFS, NOAA. Administrative Report H-98-08.

Moussali, E., and R. Hilborn. 1986. Optimal Stock Size and Harvest Rate in Multistage Life History Models. Canadian Journal of Fisheries and Aquatic Sciences 43:135-41.

Nitta, E.T., and J.R. Henderson. 1993. A Review of Interaction between Hawaii's Fisheries and Protected Species. Marine Fisheries Review 55(2):83-92.

NMFS (National Marine Fisheries Service). 1995. Unpublished Longline Logbook Data.

Okamoto, H. 1999. Comparison of CPUE and Size of Bigeye Tuna Caught by Two Types of Longline Operation. Proceeding of the $50^{\text {th }}$ Annual Tuna Conference. Lake Arrowhead, CA.

Plourde, C., and J. B. Smith. 1989. Crop Sharing in the Fishery and Industry Equilibrium. Marine Resource Economics 6:179-93. 
Pooley, S.G. 1994. Managing Longline Fishing in Hawaii-Practical Aspects of Regulatory Economics: Contributing Editor's Note. Marine Resource Economics 9:77-86. 2000. Personal communication.

Skillman, R.A., C.H. Boggs, and S.G. Pooley. 1993. Fishery Interaction between Tuna Longline and Other Pelagic Fisheries in Hawaii. NOAA Technical Memorandum NMFS (National Marine Fisheries Service), NOAA-TM-NMFS-SWFSC-189.

Squires, D., J. Kirkley, and C.A. Tisdell. 1995. Individual Transferable Quotas as a Fisheries Management Tool. Reviews in Fisheries Science 3(2):141-69.

Stollery, K. 1984. Optimal versus Unregulated Industry Behavior in a Beverton-Holt Multicohort Fishery Model. Canadian Journal of Fisheries and Aquatic Sciences 41:446-50.

TenBruggencate, J. 1999. Hawaii Swordfish Industry Imperiled. The Honolulu Advertiser, Nov. 23.

Townsend R.E. 1990. Entry Restrictions in the Fishery: a Survey of the Evidence. Land Economics 66(4):359-78.

Travis, M.D. 1999. Entry and Exit in Hawaii's Longline Fishery, 1988-1996: A Preliminary View of Explanatory Factors. Ocean-Scale Management of Pelagic Fisheries: Economic and Regulatory Issues, U. Chakravorty and J. Sibert, eds., Joint Institute for Marine and Atmospheric Research (JIMAR) Technical Report No. 99-321.

Watson, R.A., D.J. Die, and V.R. Restrepo. 1993. Closed Seasons and Tropical Penaeid Fisheries: a Simulation including Fleet Dynamics and Uncertainty. North American Journal of Fisheries Management 13:326-36.

Western Pacific Regional Fisheries Management Council (WPRFMC). 1995. Hawaii Seafood Market for Pelagic Fish. Honolulu, HI. 1997. Pelagic Fisheries of the Western Pacific Region: 1996 Annual Report. Honolulu, HI.

White, K.J. 1993. SHAZAM User's Reference Manual Version 7.0. New York: McGraw-Hill Book Company.

Wilen, J.E. 1993. Enhancing Economic Analysis for Fishery Management: Discussion. American Journal of Agricultural Economics 75:1198-99.

\section{Appendix 1}

\section{Calculation of Normalized Crew Wage}

Dividing crew income by trip length will yield biased estimates of crew wages, since both fishing and travel days are included in computation of trip length, and trips to different locations will entail different travel times. Given the nature of activities on board, wages per fishing day are expected to be higher than wages per travel day. To obtain this relationship, 95 available observations from 1993 trip data collected by Hamilton, Curtis, and Travis (1996) were used to regress the average crew income per trip with the average numbers of fishing days and travel days per trip as:

$$
\begin{gathered}
A W_{j}=-1520+1103.8 F D_{j}+309.35 T D_{j} \\
(-0.72) \quad(4.22)
\end{gathered}
$$

where $A W_{j}, F D_{j}$ and $T D_{j}$ are the average crew income and numbers of fishing days and travel days per trip for vessel $j$, respectively. The above $t$-ratios suggest that both parameters were statistically significant at the $5 \%$ level. Although the number of fishing days per trip is fixed in our model, there was some variation on average number of fishing days in the data. The mean and standard deviation were 10.6 and 2.9, respectively. Since the Breusch-Pagan test rejected the null hypothesis of 
homoscedasticity, heteroscedasticity was corrected using Shazam econometric computer software (White 1993). The negative intercept, though it is not significant, implies that certain minimum (strictly positive) fishing and travel days are required on each trip.

The above results imply that the expected wage per travel day is $28.03 \%$ (= $309.35 / 1103.8$ ) of the wage from a fishing day. Therefore, we remove this bias by calculating the normalized crew wage $(N C W)$ for a trip to area $k$ as the crew income at location $k$ divided by the "effective trip length" as follows:

$$
N C W_{k}=\frac{C I_{k}}{F D+0.2803 T D_{k}}
$$

\section{Appendix 2}

\section{Estimation of the Ratio of Catchability Coefficients}

From equation (12) define $X \equiv f\left(E_{k}, \gamma_{i}\right)=\gamma_{i 1} E_{k 1}+\gamma_{i 2} E_{k 2}$. Then the catch function equation (1) can be expressed as $C_{i, k}=\left(1-e^{-X}\right) B_{i, k}$. Since $X$ is usually between zero and unity (Deacon 1989), we can now expand $\left(1-e^{-X}\right)$ around $X=0$ as a Taylor series to get:

$$
1-e^{X}=\frac{X}{1 !}-\frac{X^{2}}{2 !}+\frac{X^{3}}{3 !}-\frac{X^{4}}{4 !}+\cdots
$$

which yields a modified catch function

$$
C_{i, k}=B_{i, k} \alpha_{i, k} X=B_{i, k} \alpha_{i, k}\left(\gamma_{i 1} E_{k 1}+\gamma_{i 2} E_{k 2}\right)
$$

in which

$$
\alpha(X)=1-\frac{X}{2 !}+\frac{X^{2}}{3 !}-\frac{X^{3}}{4 !}+\cdots
$$

where $\alpha$ is positive and monotonically decreasing with $X$ from a maximum value of unity. Equation (A5) implies that catch-per-unit-effort (CPUE) declines with increased effort due to the stock externality. Catches from tuna $\left(C_{i, k 1}\right)$ and swordfish sets $\left(C_{i, k 2}\right)$ in area $k$ can be separated from equation (A4) as:

$$
\begin{aligned}
& C_{i, k 1}=B_{i, k} \alpha_{i, k} \gamma_{i 1} E_{k 1} \\
& C_{i, k 2}=B_{i, k} \alpha_{i, k} \gamma_{i 2} E_{k 2}
\end{aligned}
$$

where $C_{i, k 1}+C_{i, k 2}=C_{i, k}$. Dividing equation (A7) by equation (A6), we obtain:

$$
\frac{\gamma_{i 2}}{\gamma_{i 1}}=\frac{C P U E_{i, k 2}}{C P U E_{i, k 1}}
$$


where $C P U E_{i, k 1}=C_{i, k 1} / E_{i, k 1}$ is CPUE for species $i$ in area $k$ for the tuna set (similarly for the swordfish set). In equation (A8), both catchability coefficients $\left(\gamma_{i 1}\right.$ and $\left.\gamma_{i 2}\right)$ are assumed constant, while CPUE is expected to fluctuate over seasons and vary across fishing locations. We can now estimate the catchability ratio $\left(\gamma_{i 2} / \gamma_{i 1}\right)$ from the CPUE ratio in equation (A8). Since the noise associated with CPUE data is expected to be large due to fluctuations in stock size within each month and non-uniformity of fish stocks within each location (five-by-five degree square), we only use data points that consist of at least 30 sets each of the tuna and swordfish sets. The resulting estimates of the catchability ratio for the five species are presented in table 1 . Okamoto (1999) computed the average CPUE ratios by swordfish and tuna sets and obtained similar results.

\section{Iterative Procedure of OLS Estimation for Catchability Coefficients}

Suppose only one type of fishing strategy is used to catch a single species. Then, given the catch function equation (A4), a series of harvests in a fishing location over consecutive periods yields the following sequence of catches:

$$
\begin{aligned}
& C_{1}=\gamma \alpha_{1} E_{1} B_{1} \\
& \vdots \\
& C_{t}=\gamma \alpha_{t} E_{t} B_{t} \\
& C_{t+1}=\gamma \alpha_{t+1} E_{t+1} B_{t+1}=\gamma \alpha_{t+1} E_{t+1}\left(B_{t}-C_{t}+R_{t}\right)
\end{aligned}
$$

where all subscripts denote the time period, and subscripts denoting species, area, and fishing strategy are omitted for notational simplicity. The net stock inflow during period $t, R_{t}$, is defined as the total fish stock inflow minus the stock outflow and natural mortality. It is positive if the inflow is greater than the outflow, and vice versa. Note that in equation (A9), the fish stock changes between periods due to harvest and in- and outmigration of fish. Expressing the previous equations in terms of $C P U E_{t} / \alpha_{t}$ and subtracting the equation for $t$ from $(t+1)$, we get:

$$
\frac{C P U E_{t+1}}{\alpha_{t+1}}-\frac{C P U E_{t}}{\alpha_{t}}=\gamma\left(-C_{t}+R_{t}\right)
$$

where $C P U E_{t}=C_{t} / E_{t}$ is catch-per-unit-effort at period $t$. To econometrically estimate $\gamma$, we assume that the Hawaii pelagic fishery is in long-run equilibrium; i.e., the expected net inflow is equal to the expected catch per period in each area. Then rewriting equation (A11) as:

$$
\frac{C P U E_{t+1}}{\alpha_{t+1}}-\frac{C P U E_{t}}{\alpha_{t}}=-\gamma\left(C_{t}-\bar{C}\right)+\varepsilon_{t}
$$

where $\bar{C}$ is the average catch per period, $R_{t}=\bar{C}+\left(\varepsilon_{t} / \gamma\right)$ and $E\left(\varepsilon_{t}\right)=0$. Equation (A11) implies that a change in CPUE adjusted by $\alpha$ (denoted by $\triangle C P U E_{a d j}$ ) between consecutive periods is a negative linear function of catch in the current period. The long-run equilibrium assumption is supported by Boggs and Ito (1993) and other studies of the Hawaii pelagic fishery, who report that species abundance estimated 
by measures such as average CPUE and average weight per fish, has not changed to any significant degree (WPRFMC 1997).

The estimated parameter $\gamma$ in equation (A11) affects the dependent variable since $\alpha_{t}$ is a function of $\gamma$ and effort level $E$ as in equation (A5). Therefore, we use an iterative procedure to estimate $\gamma$ in equation (A11); i.e., ( $i$ ) first estimate or guess $\gamma$, (ii) compute $\alpha_{t}$ and $\triangle C P U E_{a d j}$ for all observations with this tentative $\gamma$, (iii) perform another round of estimation with equation (A11) to get the new $\gamma$, and (iv) repeat the estimation procedure until the estimate of $\gamma$ converges.

A panel data set with monthly catch and fishing effort data aggregated for each five-degree square was used. Data from "swordfish-set-dominant" areas were used to estimate the catchability coefficient for swordfish with a swordfish set $\left(\gamma_{i 2}\right)$, while data from "tuna-set-dominant" areas were used to estimate the catchability coefficients for the other four species with a tuna set $\left(\gamma_{i 1}\right)$. Results from the final iteration of the OLS procedure are shown in table A1. All estimated catchability coefficients were significant at the $1 \%$ level with expected signs. The $R^{2}$ scores were relatively low, ranging from 0.1761 to 0.3716 . This is to be expected because exogenous seasonal (i.e., monthly) fluctuations in the net inflow are accounted for by the error terms in the model, and pelagic fish abundance in Hawaii is likely to be most strongly affected by factors other than local fishing activity (Boggs and Ito 1993). The $R^{2}$ scores for the three most valuable species (bigeye and yellowfin tunas and swordfish) were higher than those for albacore and striped marlin, which might reflect the relatively greater influence of fishing effort on $\triangle C P U E_{a d j}$. Although the cross-sectional, time-series data was pooled, neither autocorrelation nor heteroscedasticity was detected.

Table A1

Results of the Interactive Estimation Procedure for Catchability Coefficients, by Species

\section{Author: \\ Please provide table A1 as a simple text document. Tables as embedded pictures in a text document will not work.}

